\begin{tabular}{|c|c|}
\hline 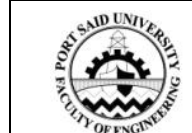 & $\begin{array}{l}\text { PORT SAID RESEARCH ENGINEERING JOURNAL } \\
\text { Faculty of Engineering - Port Said University } \\
\text { Volume } 17 \text { No. } 1 \text { pp: 32:41 }\end{array}$ \\
\hline
\end{tabular}

\title{
EVALUATION OF METHODS OF CONSTRUCTING SRTM90 FROM SRTM30
}

\author{
Ashraf Aly Elkoushy ${ }^{1}$
}

\begin{abstract}
The data released by the Shuttle Radar Topography Mission (SRTM) is at two horizontal resolutions; three arc-seconds (90 meter) globally (SRTM90), and one arc-second (30 meter) for the United States (SRTM30), whereas the one arcsecond (30 meter) for the other countries had been secreted and used only by USA. The data of SRTM90 are freely available and produced from SRTM30 by using the averaging method. The present study concerned with the accuracy evaluation of the averaging and sampling methods of creating SRTM 90 from SRTM 30. The results obtained verified that SRTM90 produced from the sampling method was better than averaging method.
\end{abstract}

\section{INTRODUCTION}

The Shuttle Radar Topography Mission (SRTM) was a space shuttle mission in 2000. The objective of this mission was to obtain RADAR data of most of the Earth's land surface to produce high resolution topographic maps. Approximately $80 \%$ of the land surface was acquired. SRTM data were organized into individual rasterized cells, or tiles, each covering one degree by one degree in latitude and longitude. The data were released at two horizontal resolutions; three arc-second (90 meter) globally (SRTM90), and one arc-second (30 meter) for the United States (SRTM30), the one arc-second (30 meter) for the other countries had been secreted and used only by USA. as discussed by [19] and [20].

The 30-meter and 90-meter SRTM data are without restraint and they are freely available for the USA by using the Seamless Data Distribution reported by [19] and [20] http://seamless.usgs.gov/ and ftp://e0mss21u.ecs.-nasa.gov/srtm/or ftp://e0srp01u.ecs .nasa.gov/srtm/. The data distributed via ftp from the Land Processes Distributed Active Archive Center (LPDAAC) are different from its Seamless Data Distribution System (SDDS, 'Seamless Server') presented by [19] and [20]. The three arc-second sampled data is generated by (SDDS 'Seamless Server') from the one arc-second called "sampling" where each three arc-second data point is generated by selecting the center sample of the $3 \times 3$ array of one arc-second points surrounding the post location. For the LP-DAAC, three arc second data, each point is the average of the nine one arc-second samples surrounding the post; "averaging".

\footnotetext{
${ }^{I}$ Civil Engineering Department, Faculty of Engineering- Port Said
} University, Port Said, Egypt, E-mail:dr.aelkoushy@gmail.com
The averaging method was evaluated in several studies such as the one conducted by [1]. The authors found that this method produced a superior product by decreasing the high frequency 'noise' usually associated with radar-derived elevation data. In this study, the averaging and sampling methods were concerned to choose the better one in terms of outcome, minimal errors produced, and correlation of SRTM 30 produced from SRTM 90.

SRTM 30 data are sampled squared at one degree of latitude and longitude where each file contains 3601 rows and 3601 columns. The rows at the north and south edges as well as the columns at the east and west edges of each cell overlap and are identical to the edge rows and columns in the adjacent cell, while SRTM 90 data are sampled at three arc-seconds and contain 1201 rows and 1201 columns with similar overlapping rows and columns.

The one second original data SRTM30 was made available to the public only for North America. Therefore, this study was concerned with a part of USA which has one arc-second (30 meter) that is available for free.

\section{METHODS OF CONSTRUCTING SRTM90 FROM SRTM30}

There are two available methods in the public domain; averaging and sampling [19] and [20]. Those methods depend on image sampling and not image resampling as was discussed extensively by [1]. Image re-sampling as discussed by [10] is the mathematical technique used to create a new version of the image with different width and/or height in pixels. Increasing the size of an image is called up-sampling while reducing its size is called down-sampling. SRTM 30 and SRTM 90 have the same dimension tile where each covering one degree by one degree in latitude and longitude. Therefore, the definition of re-sampling discussed by [1] is not established for the methods of 
construction of SRTM90 from SRTM30 as well as the methods of re-sampling using interpolation methods which had not utilized in construction of SRTM90 process.

The sampling method that labeled the central pixel is within the 3 by 3 pixel window preserving its original value in elevation. This means that every three by three pixel which have one arc-sec will be converted into one by one pixel to have a dimension of three arc-sec and a center value of nine pixels. While the averaging method labeled the average of the 3 by 3 pixel window, it produced a new value in elevation that means every three by three pixel which have one arcsec will be converted into one by one pixel to have a dimension of three arc-sec and value of average of nine pixels as shown in Figure 1.

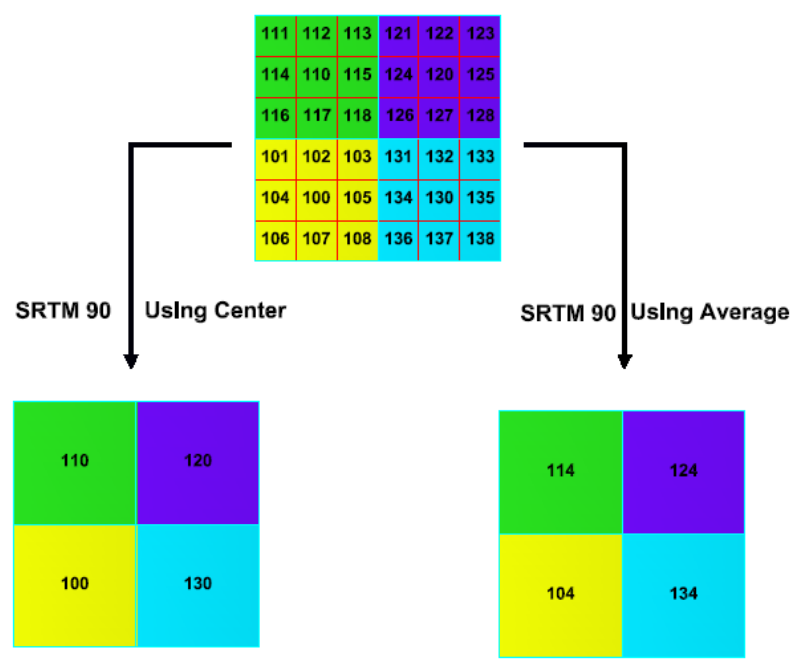

Figure (1): The sampling and averaging methods to convert SRTM30 to SRTM90.

\section{STUDY AREA}

As discussed before, the one arc second original data have been made available to the public only for North America. Therefore, this study will be considered with a part of USA which has one arc-second (SRTM30). In the present study, the area bounded between $39^{\circ} \mathrm{N}$ to $42^{\circ} \mathrm{N}$ latitudes and $104^{\circ} \mathrm{W}$ to $107^{\circ} \mathrm{W}$ longitudes was considered. This area covered three degree by three degree squared and was used only to cover the overlapped pixels while the study concerned only with the area between $40^{\circ} \mathrm{N}$ to $41^{\circ} \mathrm{N}$ latitudes and $105^{\circ} \mathrm{W}$ to $106^{\circ} \mathrm{W}$ which had area $9408 \mathrm{~km}^{2}$ (3601 rows* 3601 columns) (Figure 2). In addition, one pixels surrounded this area was taken into consideration thus, the area grows to be $9418 \mathrm{~km}^{2}$ (3603 rows* 3603 columns) with pixel size of 0.0002778 arc degrees. The selected extended areas contain smoothly sloped, sharply sloped, flat terrain and rugged mountains and have elevations varying from 1466 meter to 4293 meter (Figure 2).
The study area data of SRTM30 have the elevations in integer values and was converted into (1201 rows *1201 columns) with pixel size of 0.000833 arc degrees by using the averaging and sampling methods, thereafter the 90 meter resolution results produced (SRTM90). Figure 3.a shows the results of SRTM90 by using the averaging method where the maximum elevation was 4291 meter and the minimum elevation was 1472.7 meter. Figure 3.b shows the freely available SRTM90 by [18]; the maximum elevation was 4281 meter while the minimum elevation was 1473 meters. Figure 3.c shows the SRTM90 by using the sampling method; the maximum elevation was 4293 meter while the minimum elevation was 1472 meters. No significant differences between the two figures were detected.
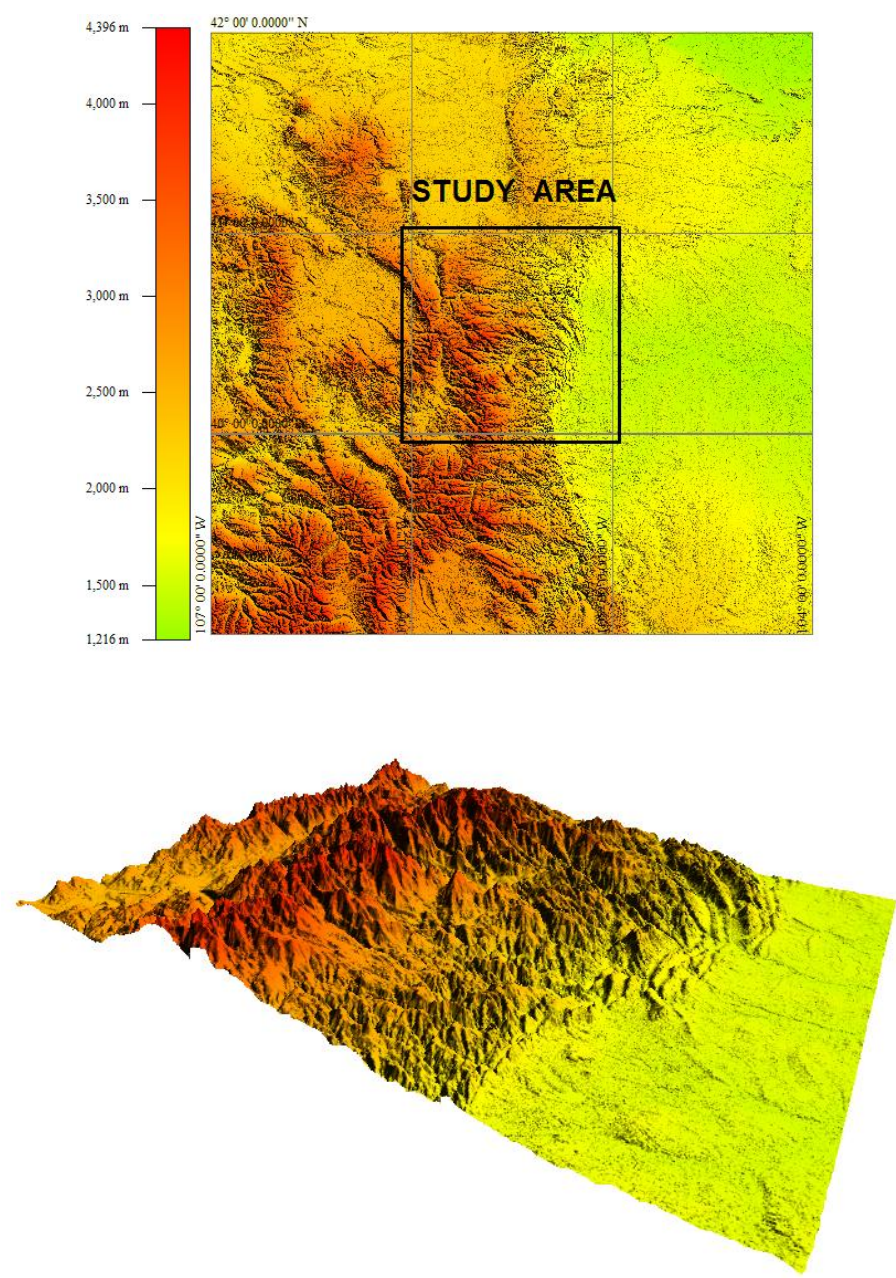

Figure (2): SRTM 30 of the Study bounded between $39^{\circ} \mathrm{N}$ to $42^{\circ} \mathrm{N}$ latitudes and $104^{\circ} \mathrm{W}$ to $107^{\circ} \mathrm{W}$ longitudes (C) NASA [13] and USGS [17] 


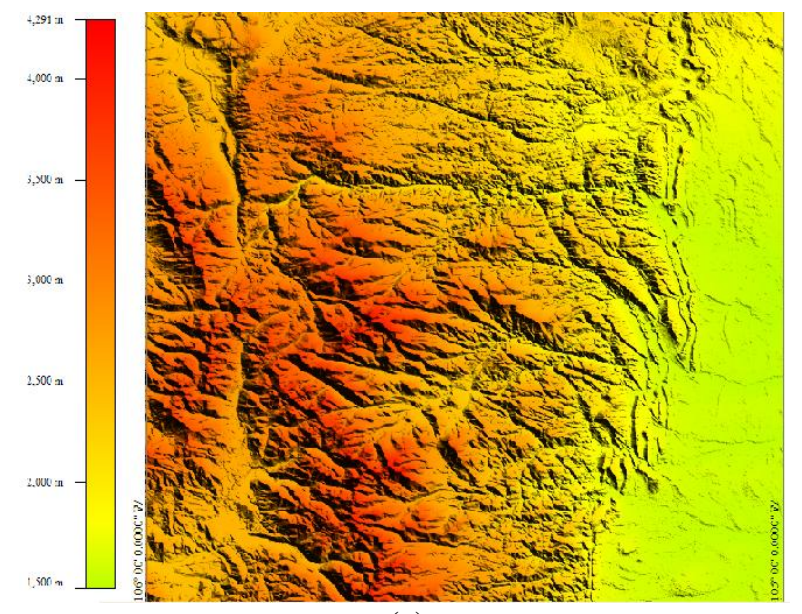

(a)

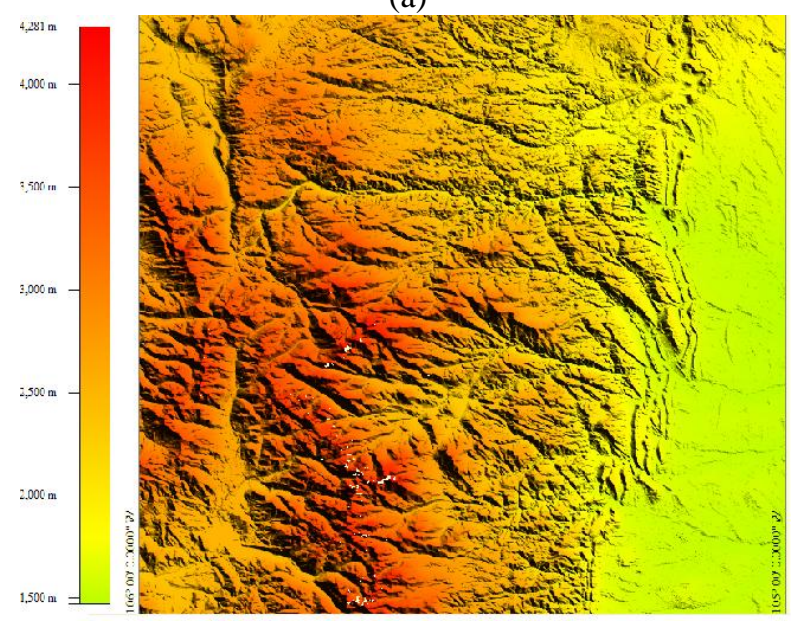

(b)

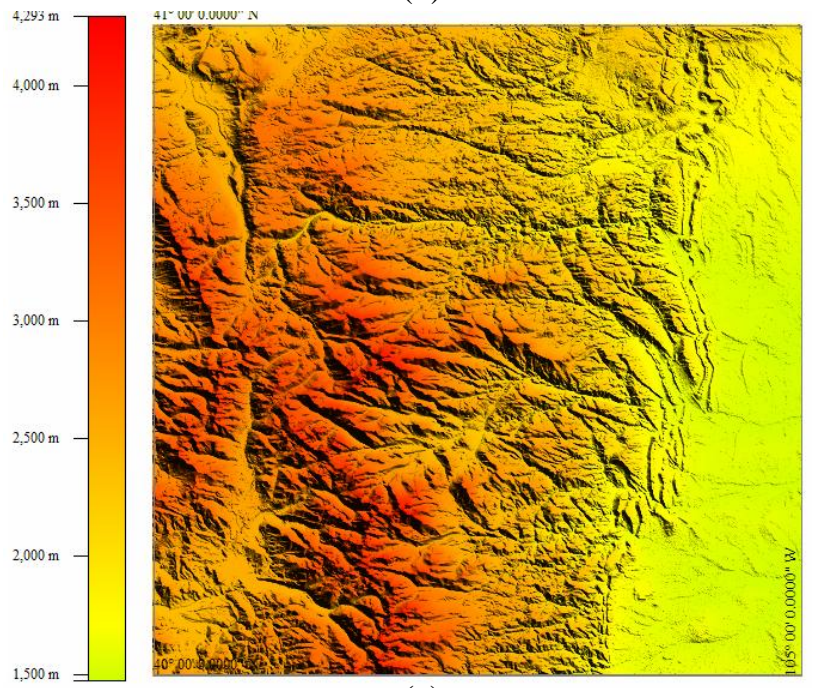

(c)

Figures (3): (a) SRTM90 reconstruction by using averaging method, (b) SRTM90 freely available with averaging method [18], and (c) SRTM90 reconstruction by using sampling method

\section{EXPERIMENTS AND RESULTS}

In order to compare the results between the produced SRTM90 and SRTM30, the pixels in the two models must have the same dimensions so that the produced SRTM90 which have $(1201 * 1201)$ pixels, each have 0.000833 arc-degree, must be converted into $(3603 * 3603)$ pixels, each three by three pixels to have 0.000273 arc-degree with the same elevation value in one by one pixel. By eliminating the surrounded edges of adjacent cells, the sample will have $(3601 * 3601)$ pixels taking into consideration the origin of axis that was presented in the center of the lower western pixel (Figure 4).

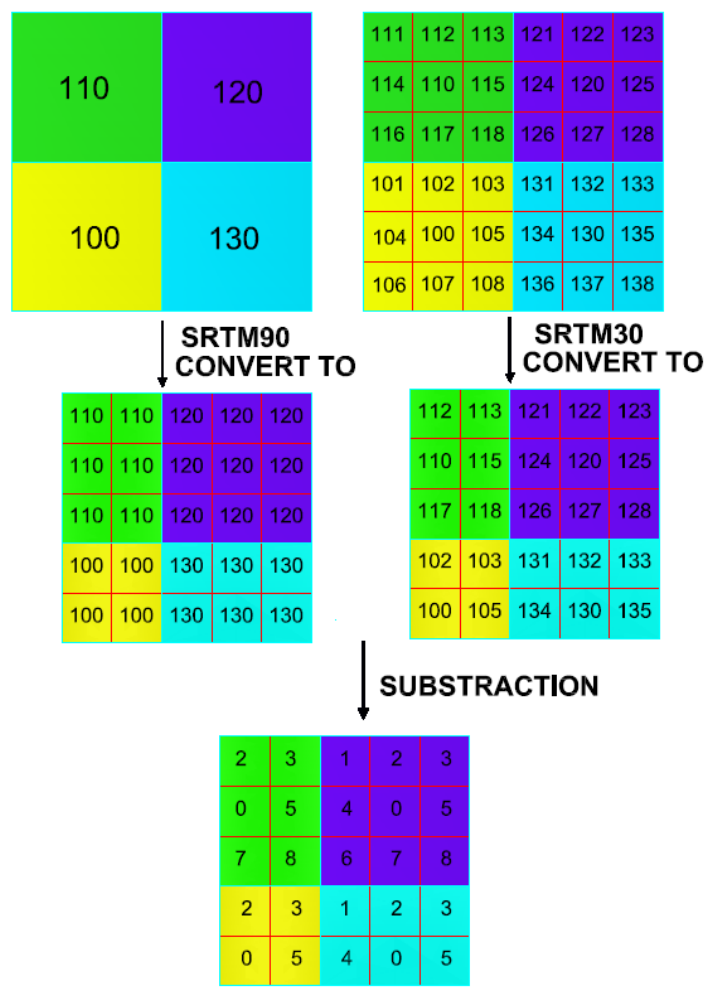

Figure (4): The pixels conversion for the lower south west corner and subtraction process of

SRTM 90 and SRTM30.

The differences between the averaging SRTM90 and SRTM30 together with the differences between the sampling SRTM90 and SRTM30 are shown in Figure 5 and Figure 6, respectively. Whereas, the minimum and maximum elevation differences by using averaging method were $-293 \mathrm{~m}$ and $215 \mathrm{~m}$ while it was $-387 \mathrm{~m}$ and $275 \mathrm{~m}$ by using sampling method, respectively.

Most of the previous work based on analysis using the maximum and the minimum elevation differences. In the current study, analysis of results depending on this consideration was found to be insignificant because the results of elevation differences may be affected only by one pixel or a few pixels with the 
maximum or minimum elevation hence, ruled the results so that analysis will be incorrect.

The elevation differences between the produced averaging SRTM90, produced sampling SRTM90 together and the freely available averaging SRTM90 are shown in Figure 7. Whereas, the minimum and maximum elevation differences by using produced averaging method were $-198 \mathrm{~m}$ and $147 \mathrm{~m}$, while it was $-263 \mathrm{~m}$ and $210 \mathrm{~m}$ by using sampling method.

It is clear that the elevation differences between the constructed SRTM90 by using averaging method and the available SRTM90 by Internet was very insignificant (about $0.20 \%$ ) of the total pixels number. This difference produces from the presence of voids in SRTM90. The sampling method provides significant elevation differences, as shown in the focused area (Figure 7, and Table 1).

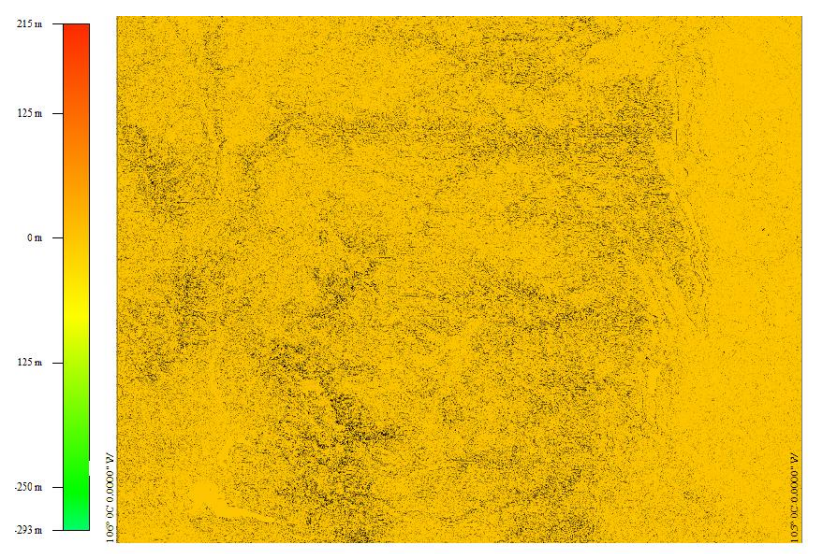

(a)

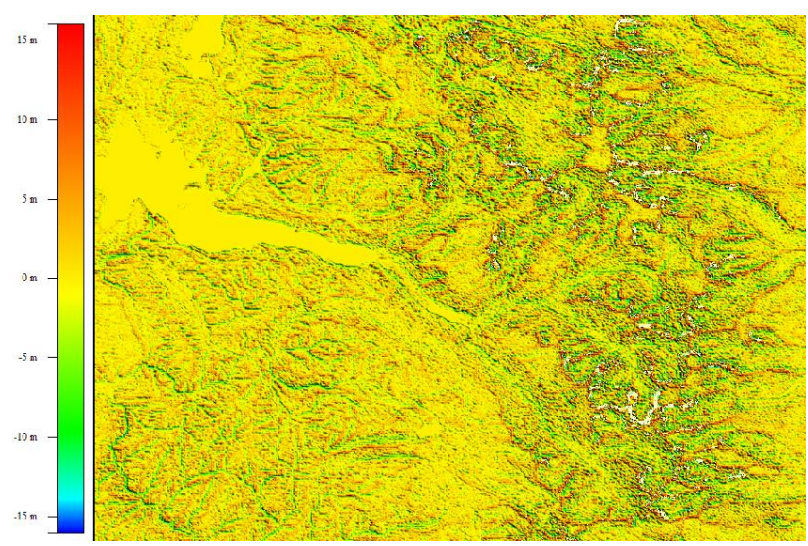

(b)

Figure (5): The elevation differences between averaging SRTM90 and SRTM30 (a) within minimum/maximum elevation differences

- $\quad 293 m / 215 m$ and (b) Focused area have elevation differences more than $\pm 16.0 \mathrm{~m}$

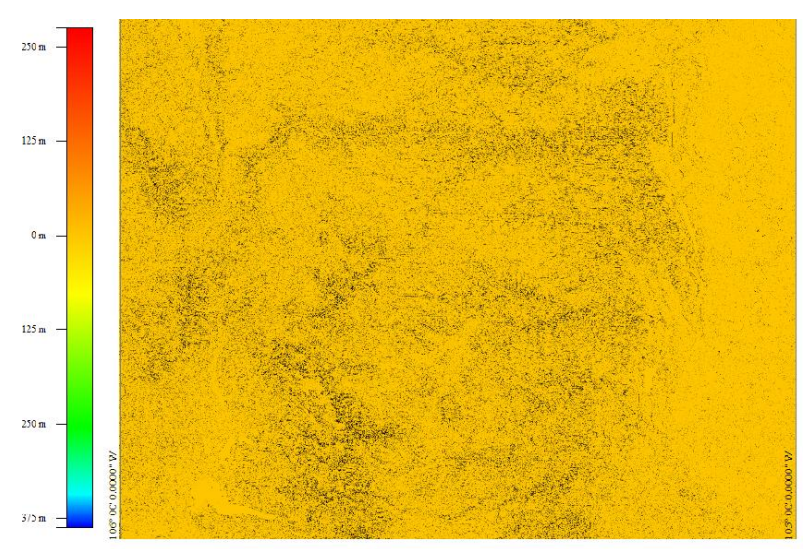

(a)

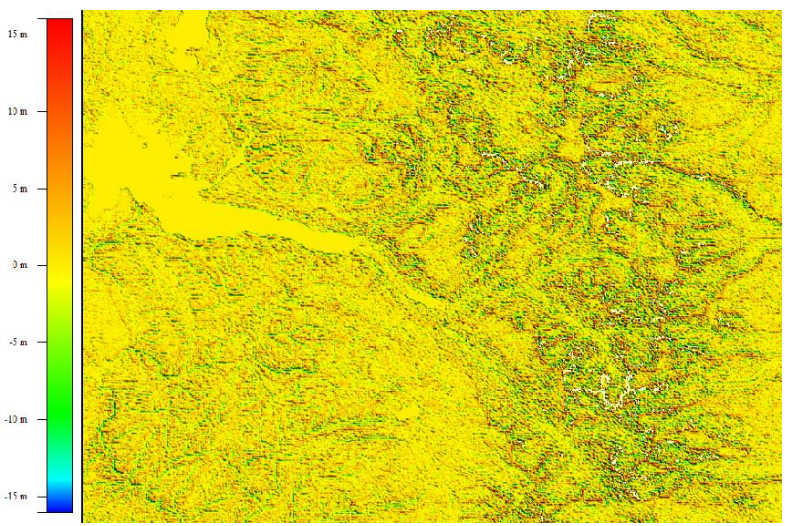

(b)

Figure (6): The elevation differences between averaging SRTM90 and SRTM30 (a) within minimum/maximum elevation differences - 387m/275m and (b) Focused area have elevation differences more than $\pm 16.0 \mathrm{~m}$

In this case study and according to the maximum/ minimum elevations differences, the averaging method gives results better than sampling method. When the difference in elevations controlled by \pm 16.0 meters which were considered as the vertical accuracy of SRTM90 as discussed in previous work [9], and from the properties of SRTM90, (Figures 5and 6) and Table 1 revealed that the sampling method gave better results than the averaging method because the existence number of white pixels (which indicate the elevation differences controlled by \pm 16.0 meters) shown in (Figures 5, and 6) by using averaging method was more than the number of white pixels by using sampling method. Thus, it must be taken into consideration during the analysis of results.

Also, the root-mean-square error (RMSE) used to describe the vertical accuracy of a DEM about elevation differences introduced during production of the data so the sampling method was superior to the averaging method where RMSE for sampling method was better than the averaging method (Table1). 


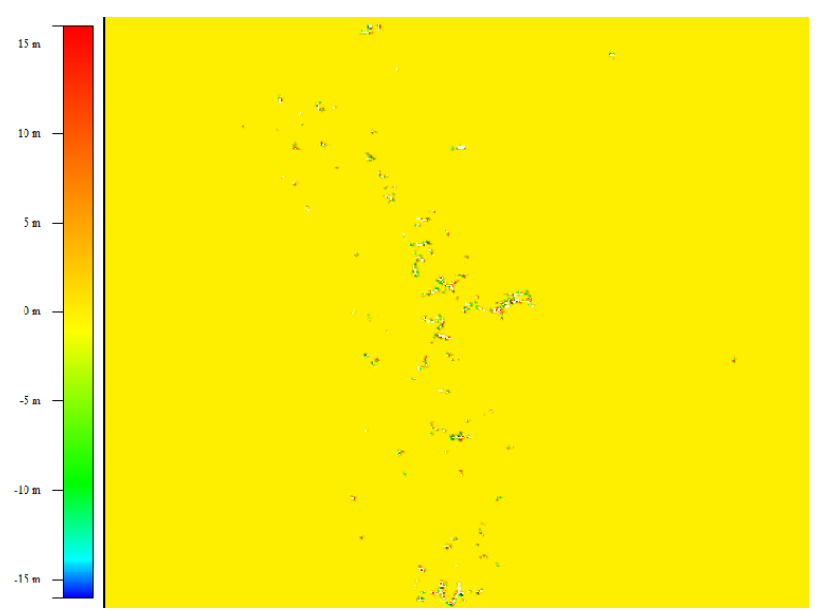

(a)

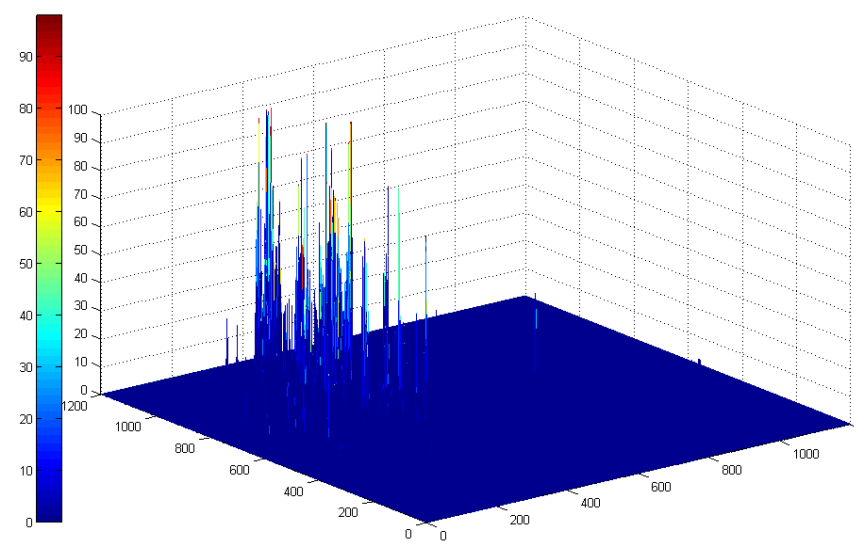

(b)

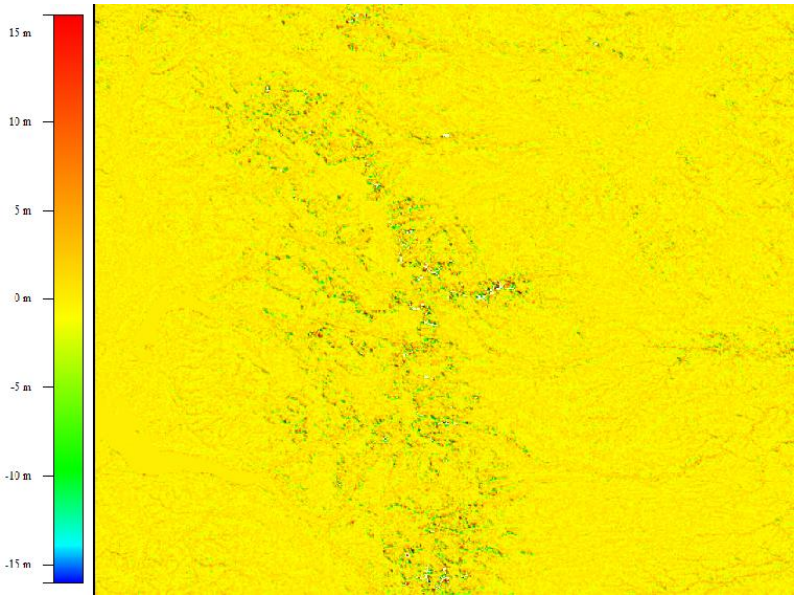

(c)

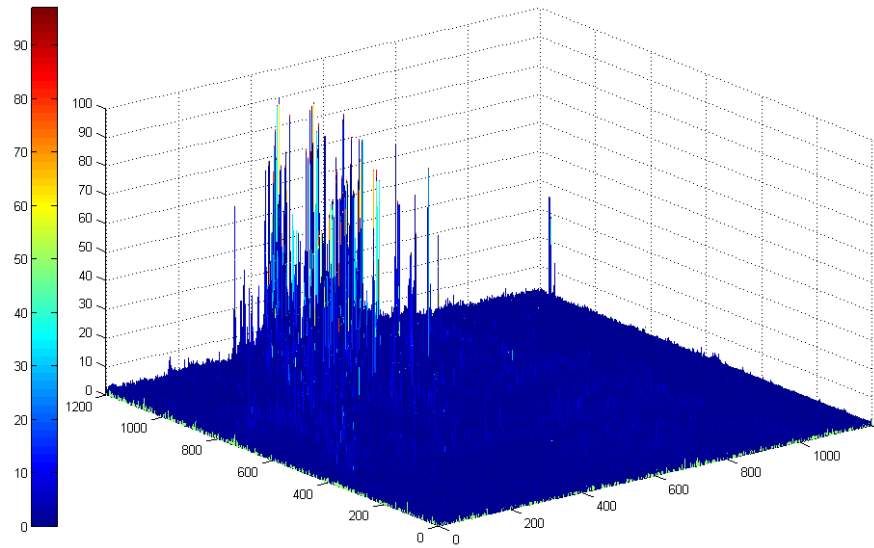

(d)

Figure (7): The elevation differences between reconstructed SRTM90 and available SRTM90 (a) by suing averaging method, (b) absolute elevation differences by using averaging method (c) by using sampling method and (d) absolute elevation differences by using sampling method.

The different numbers of pixels and the difference in elevations between SRTM90 from both methods and SRTM30 are shown in Table 1. In case of averaging method, the number of pixels controlled by \pm 16 meter was $0.23 \%$ of the total number of pixels while it was $0.18 \%$ by using the sampling method. It is obvious that the difference in elevation between zero and \pm 6 meter in value for sampling method have about $97.4 \%$, versus $96.3 \%$ for averaging method.

It was observed that, the study area contains more than $80 \%$ of mountains, hills, sharply sloped area, mountain ridges, which played a main role in results distortion and the remaining area could be considered as flat terrain or smoothly sloped which has insignificant elevation differences between the two methods and original SRTM30.
It can be seen from the focused area shown in Figure 8 that the elevation differences controlled by \pm 16 meter (the vertical accuracy within SRTM90 data) when using averaging method are more than using sampling method (Figure8 and Table 1). Likewise, the sampling method gave better results than the averaging method for in elevation differences greater than \pm 16 meter spotted in this area specially the regions between hills and mountains ridges which have a sudden slope. In contrast, both methods were comparable for the remaining study area that was virtually flat or smoothly sloped.

The results showed that the elevation differences between SRTM90 produced by averaging and sampling methods have minimum and maximum elevation differences were -148 meters and 198 meters that may erroneously thought to be great differences between the two methods however, as previously discussed, this rule could not be considered. 
Table (1): Shows the statistics differences between real SRTM 30, and created SRTM 90 using sampling method and using averaging method. Also shows the statistics differences between real averaging SRTM 90, and created SRTM 90 using sampling method and using averaging method.

\begin{tabular}{|c|c|c|c|c|c|c|c|c|}
\hline \multirow{3}{*}{$\begin{array}{c}\text { Elevation } \\
\text { Differences } \\
\text { in meter }\end{array}$} & \multicolumn{4}{|c|}{$\begin{array}{c}\text { Differences between real SRTM } 30 \text { and } \\
\text { created SRTM } 90\end{array}$} & \multicolumn{4}{|c|}{$\begin{array}{c}\text { Differences between real averaging SRTM } \\
90 \text { and created SRTM } 90\end{array}$} \\
\hline & \multicolumn{2}{|c|}{$\begin{array}{l}\text { Using averaging } \\
\text { method }\end{array}$} & \multicolumn{2}{|c|}{$\begin{array}{l}\text { Using sampling } \\
\text { method }\end{array}$} & \multicolumn{2}{|c|}{$\begin{array}{l}\text { Using averaging } \\
\text { method }\end{array}$} & \multicolumn{2}{|c|}{$\begin{array}{l}\text { Using sampling } \\
\text { method }\end{array}$} \\
\hline & $\begin{array}{l}\text { Count } \\
\text { cells }\end{array}$ & $\%$ area & $\begin{array}{l}\text { Count } \\
\text { cells }\end{array}$ & $\%$ area & $\begin{array}{c}\text { Count } \\
\text { cells }\end{array}$ & $\%$ area & $\begin{array}{l}\text { Count } \\
\text { cells }\end{array}$ & $\%$ area \\
\hline 0.00 & 3205730 & 24.72 & 4341513 & 33.48 & 1439577 & 99.80 & 587552 & 40.73 \\
\hline 1.00 & 4360290 & 33.63 & 4005133 & 30.89 & 535 & 0.04 & 591415 & 41.00 \\
\hline 2.00 & 2287309 & 17.64 & 2078848 & 16.03 & 377 & 0.03 & 175429 & 12.16 \\
\hline 3.00 & 1236715 & 9.54 & 1078513 & 8.32 & 264 & 0.02 & 53892 & 3.74 \\
\hline 4.00 & 709197 & 5.47 & 590981 & 4.56 & 191 & 0.01 & 18190 & 1.26 \\
\hline 5.00 & 421863 & 3.25 & 334858 & 2.58 & 151 & 0.01 & 7072 & 0.49 \\
\hline 6.00 & 260129 & 2.01 & 196798 & 1.52 & 134 & 0.01 & 3248 & 0.23 \\
\hline 7.00 & 163632 & 1.26 & 118317 & 0.91 & 97 & 0.01 & 1635 & 0.11 \\
\hline 8.00 & 103502 & 0.80 & 72383 & 0.56 & 87 & 0.01 & 963 & 0.07 \\
\hline 9.00 & 67010 & 0.52 & 45468 & 0.35 & 68 & 0.00 & 609 & 0.04 \\
\hline 10.00 & 44319 & 0.34 & 29026 & 0.22 & 52 & 0.00 & 400 & 0.03 \\
\hline 11.00 & 28942 & 0.22 & 18953 & 0.15 & 68 & 0.00 & 278 & 0.02 \\
\hline 12.00 & 19396 & 0.15 & 12775 & 0.10 & 55 & 0.00 & 204 & 0.01 \\
\hline 13.00 & 13357 & 0.10 & 8821 & 0.07 & 44 & 0.00 & 182 & 0.01 \\
\hline 14.00 & 9347 & 0.07 & 6221 & 0.05 & 39 & 0.00 & 159 & 0.01 \\
\hline 15.00 & 6745 & 0.05 & 4698 & 0.04 & 34 & 0.00 & 114 & 0.01 \\
\hline$\geq 16$ & 29718 & 0.23 & 23895 & 0.18 & 628 & 0.04 & 1059 & 0.07 \\
\hline $\begin{array}{c}\text { Total Pixels } \\
\text { Number }\end{array}$ & \multicolumn{4}{|c|}{12967201} & \multicolumn{4}{|c|}{1442401} \\
\hline \multicolumn{9}{|c|}{ Statistics } \\
\hline Mean Diff. & \multicolumn{2}{|c|}{0.0001} & \multicolumn{2}{|c|}{-0.002} & \multicolumn{2}{|c|}{0.0024} & \multicolumn{2}{|c|}{-0.003} \\
\hline RMSE & \multicolumn{2}{|c|}{3.011} & \multicolumn{2}{|c|}{2.692} & \multicolumn{2}{|c|}{0.807} & \multicolumn{2}{|c|}{1.681} \\
\hline Min. Elev. & \multicolumn{2}{|c|}{1473} & \multicolumn{2}{|c|}{1472} & \multicolumn{2}{|c|}{1473} & \multicolumn{2}{|c|}{1473} \\
\hline Max. Elev. & \multicolumn{2}{|c|}{4291} & \multicolumn{2}{|c|}{4293} & \multicolumn{2}{|c|}{4281} & \multicolumn{2}{|c|}{4281} \\
\hline Min. Diff. & \multicolumn{2}{|c|}{-293} & \multicolumn{2}{|c|}{-387} & \multicolumn{2}{|c|}{-198} & \multicolumn{2}{|c|}{-263} \\
\hline Max. Diff. & \multicolumn{2}{|c|}{215} & & & & & 2 & \\
\hline
\end{tabular}




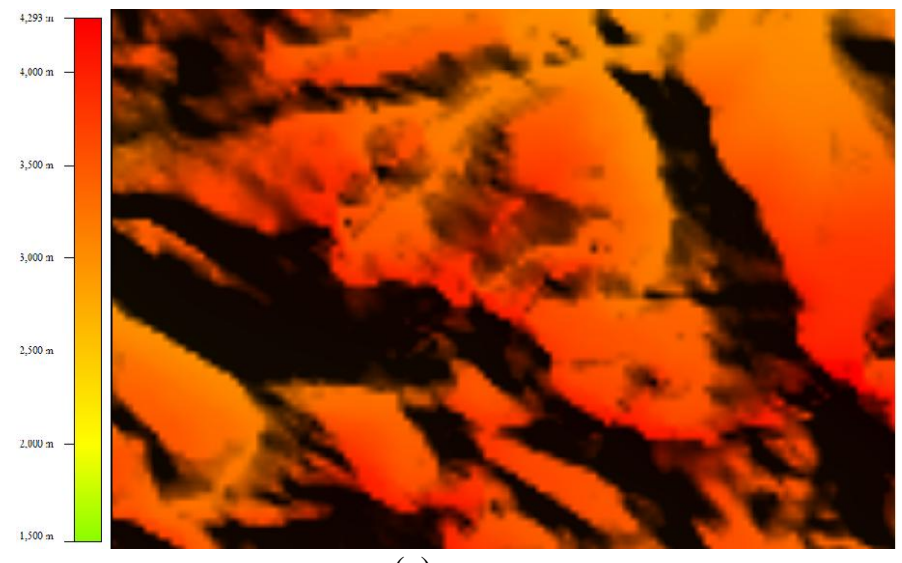

(a)

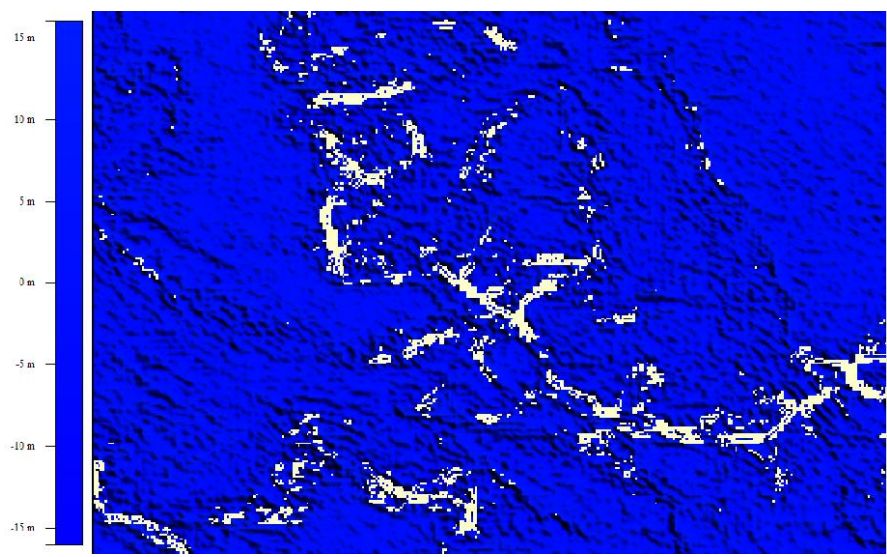

(b)

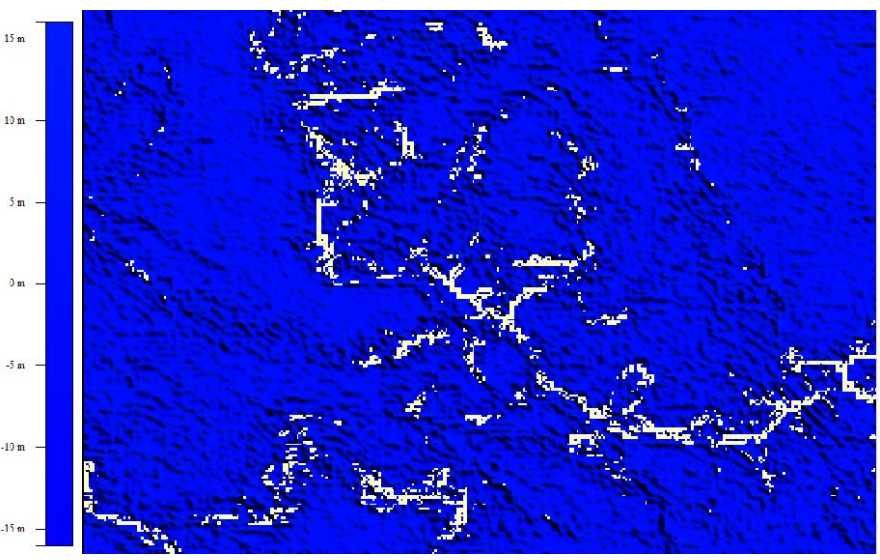

(c)

Figure (8): (a) A focused part of the study area,

(b) Elevation Differences between real SRTM 30 and created averaging SRTM90 more than $\pm 16 \mathrm{~m}$, (c) Elevation Differences between real SRTM30 and created sampling SRTM90 more than \pm 16 m more than $\pm 16 \mathrm{~m}$ (The white pixels indicate that the elevation differences is more or less than $16 \mathrm{~m}$ )

To verify these results, two random sections were drawn; one section in the mountains region and the other in the smoothly sloped region (Figures 9 and 10). Figure 9 shows a section which was taken randomly through mountains region and have a length of approximately $815 \mathrm{Km}$ with elevations varying from $2299 \mathrm{~m}$ to $4115 \mathrm{~m}$.

This figure showed that the elevation differences by using the two methods is almost around the value \pm 10 $\mathrm{m}$, a few points only extend beyond this differences. The elevation differences between averaging and sampling methods are within \pm 3 meter which are presented in Figure 9.

Figure 10 revealed a section taken randomly through smoothly sloped region that have a length about $480 \mathrm{Km}$ and its elevations varied from $1477 \mathrm{~m}$ to $1615 \mathrm{~m}$. The elevation differences by using the two methods is almost around the value $\pm 2.5 \mathrm{~m}$, a few points only extend beyond this differences. The elevations differences between averaging and sampling methods are within $\pm 1 \mathrm{~m}$ were also illustrated.

\section{CONCLUSION}

Elevation differences between SRTM30 and SRTM90 developed by averaging and sampling methods could be considered typical of plane and smoothly sloped regions. The SRTM90 data could be used with aware satisfaction in flat regions having insignificant elevation differences, but in sharply sloped, ridges, and mountains regions present great differences errors specially the regions between hills and mountains ridges which having a sudden slope. In such regions, it is preferable to use sampling method since this method presents elevations vertical accuracy \pm 16 meter better than the averaging method. The present study proved that the sampling method had reliable results better than the averaging method over all the study area depending on RMSE, and error analysis.

The main advantage of SRTM90 using sampling method is the presence of more than $11 \%$ of the original points from SRTM30 and this advantage may be helpful, when using the interpolation methods to produce SRTM30 from SRTM90.

Acknowledgment: The author acknowledges

NASA, USGS and JPL for providing the SRTM data set. The effort of those who offered reports and sources are greatly appreciated which was helpful and commonly spread by internet.

Note: All data used in this study are freely available from the sources mentioned in the text (see also references) 

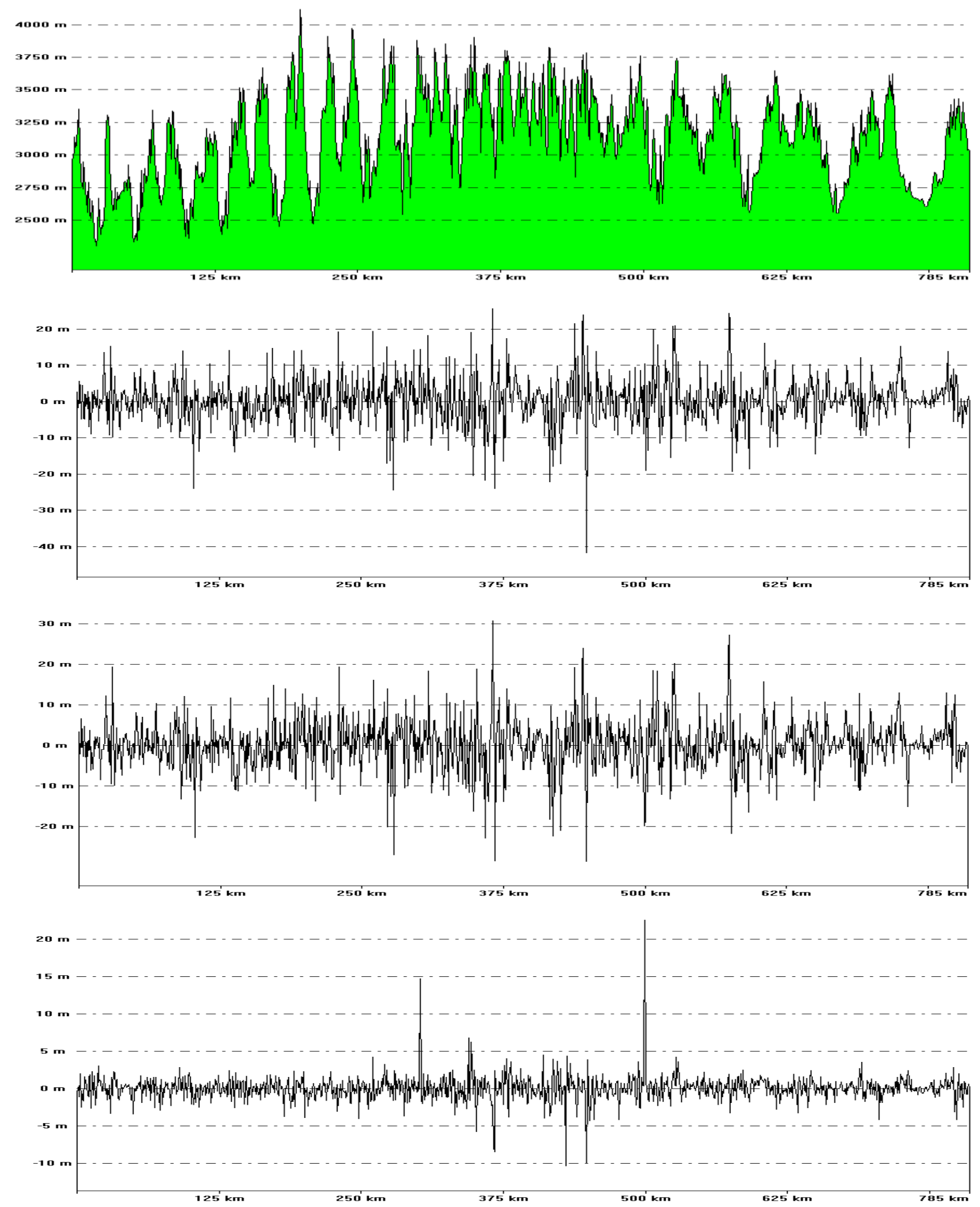

Figure (9): (a) The terrain elevations for random tested area through the mountains area.

(b) The elevation differences between SRTM30 and SRTM90 by using averaging

(c) The elevation differences between SRTM30 and SRTM90 by using sampling.

(d) The elevation differences of SRTM90 produced by averaging and sampling. 

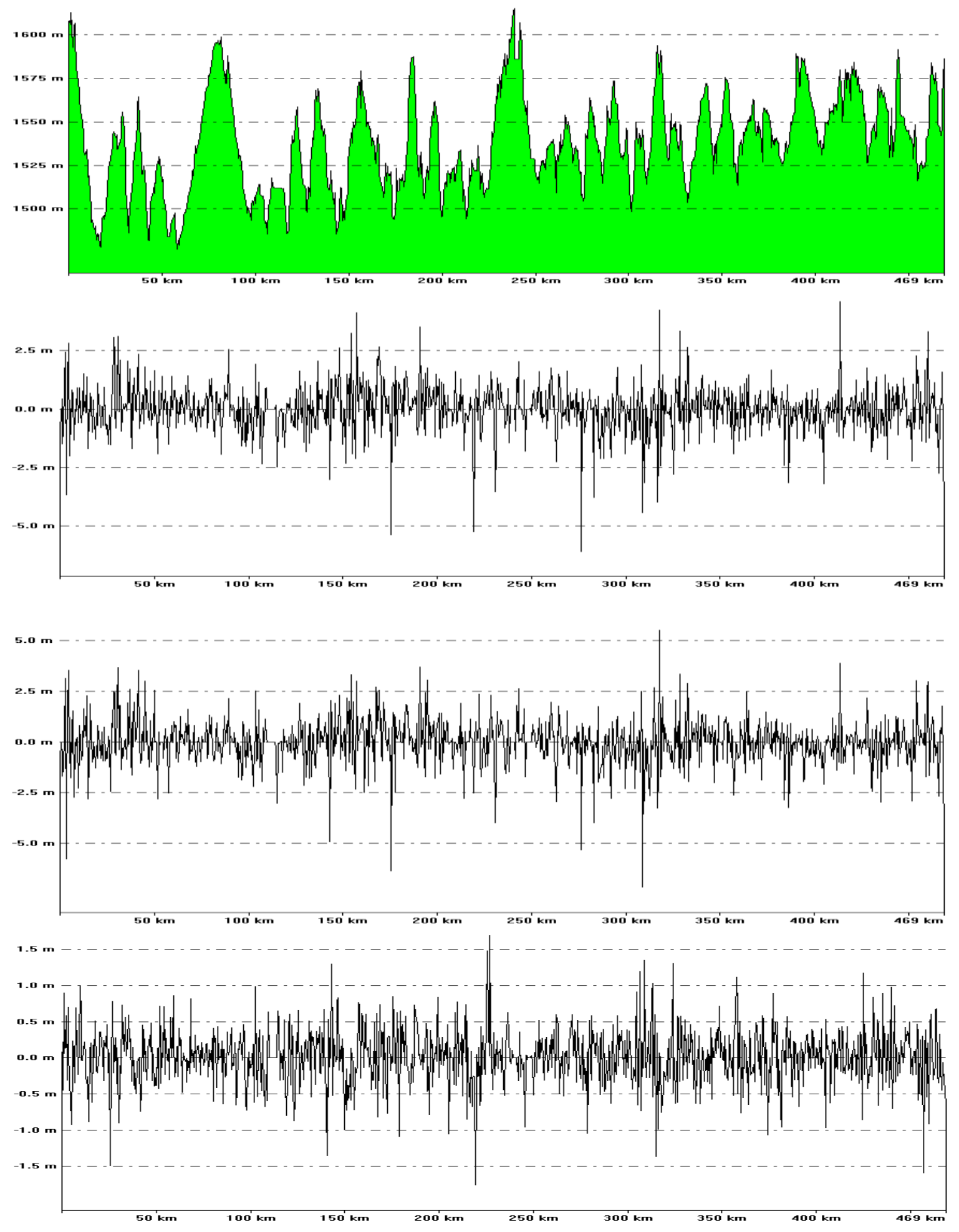

Figure (10): (a) The elevations for random tested area through the gradual changed area.

(b) The elevation differences of between SRTM30 and SRTM90 by using averaging.

(c) The elevation differences of between SRTM30 and SRTM90 by using sampling.

(d) The elevation differences of SRTM90 between averaging and sampling. 


\section{REFERENCES}

[1] Becek K., (2007) "Comparison of Decimation and Averaging Methods of DER's Resampling" Proceedings of the Map Asia Conference 2007.

[2] David, K., Mark, D. \& Derek, S. (2002) "What's the Point? Interpolation and Extrapolation with a Regular Grid DEM", Conference ACRS 2002.

[3] Grohmann, C.H., (2006), "Resampling SRTM 3"with Kriging”, GRASS/OSGeo-News 2006 volume 4 December 2006 20-26.

[4] Gorokhovich Y., Voustianiou A., (2006), "Accuracy Assessment of the Processed SRTMbased Elevation Data by GIAR Using Field Data from USA and Thailand and its Relation to the Terrain Characteristics", Remote Sensing of Environment 104 (2006) 409-415.

[5] Gonçalvesa, J. A., Morgadob A. M. (2008), "Use of the SRTM DEM as Georeferencing Tool by Elevation Matching", ISPRS Vol. XXXVII. Part B2. Beijing 2008.

[6] Hermsmeyer D., Guretzki M., Rüffer J., Krüger S., (2008) "Complete SRTM digital Elevation Data for the Arabian Peninsula", Study Carried out by Phoenics GmbH using ArcGIS (Spatial Analyst Module).

[7] Hwang, J, \& Shih, T. (1997) "A Comparison of Bilinear Interpolation, Cubic Convolution, Brownian Interpolation with Least Squares Matching " ,Conference ACRS 1997

[8] Jarvis A., Rubiano J., Cuero A. (2006), “ Comparison of SRTM derived DEM vs. Topographic Map Derived DEM in the Region of Dapa”, CIAT report 2006.

[9] Keeratikasikon C., Trisirisatayawong I., (2008) "Reconstruction of 30m DEM from 90m SRTM with Bicubic Polynomial Interpolation Method", ISPRS Vol. XXXVII. Part B12. Beijing 2008.

[10]Sachs J., (2001) "Image Resampling”, Copyright (C) 2001 Digital Light \& Color.

[11] Mouratids A., Briolep P., Katsamblos K.,(2010 ) " SRTM 3DEM (versions 1, 2, 3, 4) Validation by Means of Extensive Kinematic GPS measurements: a Case Study from North Greece " ,International Journal of Remote Sensing Vol. 31, No. 23, 10 December 2010, 6205-6222.
[12] Miliaresis G.Ch, Paraschou C.V.E., (2005), "Vertical Accuracy of the SRTM DTED Level 1 of Crete", International Journal of Applied Earth Observation and Geoinformation 7 (2005) 56 4959.

Other Web sites of interest:

[13] NASA/JPL SRTM: http://www.jpl.nasa.gov/srtm/.

[14] NGA: http://www.nga.mil/

[15] USGS: http://seamless.usgs.gov/.

[16] SRTMFILL:

http://www.3DNature.com/SRTMFILL.html/.

[17] U.S. Geological Survey, EROS Data Center: http://edc.usgs.gov/.

[18] http://dds.cr.usgs.gov/srtm/version2 1/SRTM3/.

[19] http://dds.cr.usgs.gov/srtm/version2_1/Documentati on/SRTM_Topo.pdf.

[20]http://dds.cr.usgs.gov/srtm/version2_1/SRTM30/srt m30 documentation.pdf/. 